\title{
Entre interações de risco e tensões do afeto
}

\author{
Norma Discini de Campos
}

Resumo: A partir do cotejo entre o pensamento de Landowski e de Zilberberg, dois semioticistas que interrogam a regência do sensível na instalação do sentido do mundo, este trabalho discute a emergência de estilos a partir das coerções semânticas e estéticas de duas esferas da comunicação: a midiática e a literária. Para isso, pensamos no corpo do ator da enunciação na relação necessária estabelecida com o ator do enunciado.

Palavras-chave: corpo; estesia; presença; semiótica.

\begin{abstract}
Between interactions of risk and tensions of the affection - From the comparison between the thought of Landowski and Zilberberg, two semioticians who question the regency of the sensitive in the installation of the meaning of the world, this paper discusses the emergence of styles from the semantic and aesthetic constraints of two spheres of communication: the mediatic and the literary. In order to achieve this, we consider the body of the actor of the enunciation in the necessary relationship established with the actor of the utterance.
\end{abstract}

Keywords: body; esthesia; presence; semiotics.

\section{Notas iniciais}

A inquietação a respeito dos meios segundo os quais o sensível rege o inteligível, na orientação imprimida a um corpo que pode ser pensado como campo de presença ou campo de percepção, é conduzida peculiarmente por duas correntes da semiótica contemporânea - de um lado, Landowski, com a noção de interações de risco (2005a), de outro, Zilberberg, com as questões relativas às tensões do afeto (2006). Landowski, ao discorrer sobre o estatuto do outro nas interações sensíveis entre o sujeito que percebe e o mundo percebido, atribui um "estatuto actorial" para as coisas do mundo e assim se refere a elas: "manifestações dotadas, enquanto realidades materiais, de uma consistência estésica, isto é, de qualidades ditas, elas também, 'sensíveis' [...] oferecidas à nossa percepção sensorial" (LANDOWSKI, 2005b, p. 18). Deduzimos que as virtualidades da língua, realizadas em discurso, confirmam, para a própria língua, uma "consistência 
estésica" - entendida, a estesia, como um viés da sensibilidade. Paolo Fabbri, ao fazer a introdução à obra Da Imperfeição (GREIMAS, 2002), compõe este comentário: "A. J. Greimas, semioticista e linguista, optou pelo estésico, isto é, pelo componente afetivo e sensível da experiência cotidiana" (FABBRI, 2002, p. 95).

Se pensarmos, a partir de Zilberberg, numa foria, que - como "força que leva adiante" o sentido do mundo ou como "força que transporta as categorias semânticas" (TATIT, 2002, p. 199) - "predica, conota os conteúdos", sendo, portanto, "coextensiva" a eles (ZILBERBERG, 2006, p. 131), deparamos com uma diretividade do sentir, articulada entre a "tensão" e o "relaxamento" (ZILBERBERG, 2006, p. 132). No desempenho de uma função relativa ao que é "missivo" (do latim missivus, que se remete ou envia ou faz seguir), articula-se tal força segundo um fazer remissivo (ligado a um gesto nomeado como cessar) e um fazer emissivo (ligado a um gesto nomeado como cessar de cessar). Lá, um princípio de descontinuidade; cá, um princípio de continuidade. Por meio dessa acepção da noção de foria, atingimos a problemática do tempo que, como um "grande sintaxista" (ZILBERBERG, 2006, p. 135), apresenta-se articulado ao espaço nas profundidades figurais, para o que é levado em conta como duração.

Para discutir os regimes de presença, Landowski (2005a) também problematiza a relação entre o contínuo e o descontínuo, mas atribui a essas noções outras acepções, enquanto traz à luz da análise o que podemos entender como dois eixos da percepção: um organizado segundo a previsibilidade e a regularidade; outro, segundo o imprevisto e a ruptura. Lá, os polos alinhados ao contínuo (regime da junção); cá, os polos alinhados ao descontínuo (regime da união). Na previsibilidade, a programação e a manipulação; no imprevisto, o acidente e o ajustamento. A ideia de risco orienta essas interações.

Em princípio, radicam-se ambos os semioticistas:

- $\quad$ na preocupação de investigar o sentido que emerge da relação expressão / conteúdo constitutiva dos textos;

- na tradição dos estudos discursivos, a qual parte do conceito de que a todo enunciado pressupõe-se uma enunciação, que nesse enunciado mesmo se encarna;

- $\quad$ num método de investigação não restrito às relações sintático-semânticas desdobradas em níveis (fundamental, narrativo e discursivo) no interior do percurso gerativo do sentido;

- $\quad$ na organização do sensível segundo a articulação entre o contínuo e o descontínuo.

A partir daí, os pensamentos de um e de outro fundam, cada qual, uma perspectiva teórica e, ao fazê-lo, juntos acabam por oferecer novos rumos às investigações semióticas sobre o sensível. 


\section{Corpo estésico e semântico}

Ao falar em corpo, pensamos no ator - da enunciação e do enunciado. Aquele interessa como efeito de identidade que respalda um estilo e está cravado num "actante da comunicação", lembrado por Greimas e Courtés (2008, p. 21) como desdobrado em narrador e narratário. O actante enunciador, enunciado por meio de um narrador, para tornarse ator necessita do desempenho de papéis temáticos próprios ao produtor de sentidos. Esses papéis discursivizam a geração do sentido desde a timia fundamental, alinhada a uma foria bipartida em euforia e disforia. Os valores - ainda abstratos e dispostos conforme as operações sintáticas orientadas no nível fundamental - no nível narrativo se compõem segundo a própria investidura em um objeto, emergente da junção com o sujeito do fazer. Às operações, que suportam a orientação da axiologia fundamental, segue a actancialização narrativa, amparo, no discurso, dos papéis temáticos do ator da enunciação. São estes os papéis articulados pela moralização do mundo, o que se torna possível por meio das apreciações (implícitas ou explícitas) do narrador em relação aos componentes do enunciado: o tratamento ético imprimido ao ator do enunciado é um caso dessa moralização, tal qual desenvolvido por Fiorin (1996) ao estudar a categoria da pessoa. O corpo enunciativo é em princípio sintático e por fim encarnado: um corpo semântico.

Entretanto, em qualquer discurso, o ator da enunciação encarna-se também estesicamente. A encarnação semântica radica-se nas movimentações próprias à axiologia fundamental, em que ainda como uma quase-presença o sujeito projeta escolhas entre o que é eufórico e o que é disfórico. Continua a semantização da pessoa discursiva como uma quase-presença no nível narrativo, em que a junção entre o sujeito e o objeto implica um sujeito que deseja e um objeto desejável, lado a lado com outros tipos de junção, como a que emparelha o querer de um sujeito com um objeto prejudicial ou nocivo, entre outras. Continua ainda a semantização da pessoa na transformação dos objetos do nível narrativo em temas e figuras do nível discursivo, acompanhados daquele tratamento ético oferecido a tais concretizações das relações mais gerais e abstratas da geração do sentido. No nível discursivo, temos a presença realizada; no nível narrativo, a presença atualizada; no fundamental, a presença virtualizada.

O corpo é semântico, tal qual processado no interior do percurso gerativo do sentido, o que culmina com os papeis actanciais preenchidos pelos papeis temáticos do ator da enunciação. É também estésico, o que remete ao sensível, que impregna todos os componentes da geração do sentido e se expande na conotação estética do próprio lógos, a palavra enunciada, e do éthos, a imagem do enunciador. Assim concebido e alinhado ao pensamento de Landowski, o corpo está plantado tanto nos regimes de sentido pautados pela programação e pela manipulação como nos regimes relativos ao acidente e ao ajustamento. Trazendo à luz as vizinhanças entre os princípios relativos às "interações de risco" (LANDOWSKI, 2005a) e a orientação própria a uma gramática tensiva (ZILBERBERG, 2011), 
entendemos que a definição supracitada dos regimes de sentido depende do acento e da tonicidade do estésico imprimidos sobre o semântico. Para isso levamos em conta o ator da enunciação processado segundo dois perfis, o judicativo e o sensível. Processo implica aspecto, noção que, herdada da tradição linguística, aplica-se à categoria de pessoa. Uma pessoa discursiva aspectualizada desenvolve-se segundo aqueles dois distintos vieses da observação de mundo e inclina-se para o regime das continuidades (programação/ manipulação) ou das descontinuidades (acidente/ ajustamento) na definição de um corpo, fundamento do estilo. Do primeiro eixo, desponta um corpo perfectivo, que não deixa brechas para a premência do sensível. O contrário acontece com o segundo eixo - o que pensamos a partir da obra citada de Landowski.

Com base nos pressupostos teóricos formulados por Zilberberg e Landowski, podemos cotejar duas esferas da comunicação - a midiática e a literária - com vistas a depreender a especificidade de cada uma delas. Distintas condições de engendramento do sentido favorecidas por meio das coerções de cada esfera oferecem possibilidades para a emergência de diferentes estilos, concebidos cada qual como a discursivização de um corpo que julga as coisas do mundo e que as sente na percepção. Podemos começar por investigar os regimes do sentido propostos por Landowski como distintivos de uma esfera e outra. Na esfera midiática da comunicação, há indicações de que temos a dominância do semântico sobre o estésico, mediante a prevalência do regime de junção entre sujeito discursivo e mundo discursivizado. É a junção que, articulada como conjunção e disjunção, parte de certa descontinuidade entre sujeito e objeto, impelidos um ao outro na procura exercida por aquele (sujeito) na direção deste (objeto) e mantida a assimetria de lugares entre o sujeito da busca e o objeto buscado. Aí, o corpo semantizado funda o éthos discursivo e encontra meios para a própria descrição no recurso metodológico do percurso gerativo do sentido, respeitadas as ampliações conceituais feitas por Landowski sobre a manipulação, etapa da narratividade.

Com o corpo estésico, mergulhamos no que se pode nomear "precondições da geração do sentido", na medida em que a enunciação não se restringe ao fazer persuasivo do enunciador, que procura a adesão esperada como fazer interpretativo do enunciatário. Nessa manipulação, fundante do contrato de confiança enunciativo, o corpo se aspectualiza como perfectivo, já que tudo se resolve na realização do próprio contrato fiduciário. Com o corpo estésico é diferente, o que podemos reconhecer na literatura, cotejada com o discurso midiático. Aquela esfera da comunicação oferece indicações de que, no seu interior, contrariamente ao que ocorre com o viés midiático, encontramos a dominância do estésico (a conotação sensível do lógos e do éthos) sobre o semântico (a conotação judicativa do lógos e do éthos). Lado a lado com Landowski, deduzimos que, na esfera literária da comunicação, isso se torna possível graças à prevalência do regime da união entre sujeito e mundo. Cada uma das esferas citadas faz emergir relações peculiares entre a língua e o discurso, o que acaba por contemplar a dominância 
da função - poética ou utilitária da linguagem - como fundadora de estilos. Na medida em que se atenuam as coerções da estesia, ficam robustecidas as características da função utilitária da linguagem.

As precondições da geração do sentido, contempladas segundo o pensamento de Zilberberg (2006, p. 145) num nível tensivo e figural, remetem ao que o semioticista entende por princípios de "etização" e de "estetização". A etização relaciona-se à noção de éthos, de um sujeito ético, responsável e de vontade, apto a tomar partido na história do mundo: um sujeito ligado à interpretação moralizante desse mundo; um éthos, enfim, concebido como decorrência discursiva da noção retórica de éthos (ARISTÓTELES, 1979). A estetização, que se relaciona à noção de estesia (do grego aísthesis, sensação + ia), entendida como o que precede o estético e subjaz a ele, não se aparta do viés semântico na constituição do corpo. A estesia perpassa todos os discursos, ainda que seja por meio de valências mitigadas ou mínimas da tonicidade sensível do sentido. O jornal tem sua estética.

Como princípio de conotação estésica do lógos (a palavra discursivizada) e do éthos (a imagem de quem diz, dada por um modo próprio de dizer) - a estesia está em todos os enunciados. Enquanto isso radica o éthos necessariamente conotado, como já previu Barthes (1975, p. 203), para quem o "éthos é, no sentido próprio, uma conotação". O semiólogo enfatiza: "O orador enuncia uma informação e, ao mesmo tempo, afirma: sou isso, sou aquilo" (BARTHES, 1975, p. 203) - seguindo de perto o que fala o Estagirita em sua Retórica (ARISTÓTELES, 1979). A novidade de Barthes é entender o éthos como necessariamente conotado. Desse modo, a estesia se alia aos movimentos semânticos da geração do sentido de qualquer discurso. Antes disso, porém, ela se emparelha a uma foria não servil à semântica. A foria de inclinação semântica está articulada segundo as avaliações do que é eufórico (valor do bem) e do que é disfórico (valor do mal), o que subentende valorações axiológicas dos valores, as quais radicam a modalização dos objetos de valor como desejáveis ou repudiáveis, entre outras. A dimensão semantizada da foria funda os papéis temáticos do ator e orienta a ideologização discursiva dos valores narrativos, trazendo o discurso de volta para a sociedade e para a história. Aí, temos princípios que, se orientam o perfil judicativo do ator da enunciação, respaldam-se no que Landowski ressalta como a "manipulação" e no que Zilberberg ressalta como etização. Como condição de produção do sentido, o lógos apresenta-se segundo uma estesia mitigada ou minimizada, a depender das esferas de comunicação e dos gêneros que nelas circulam - tudo considerado em cotejo analítico. Numa reportagem, comparada a um gênero literário, podemos partir da hipótese de que se firma como prioridade a semantização do mundo, enquanto a estesia permanece em quase apagamento. Conforme Landowski, predomina na reportagem a relação manipulador/ manipulado, juntamente com seu elemento complementar, a programação. Segundo Zilberberg (2006, p. 145), estamos, no campo midiático, diante de uma etização que implica a ativação do sujeito e a desativação do objeto. Para o objeto, pensamos a língua discursivizada 
nessa esfera da comunicação ordinária: é o lógos, que, como palavra enunciada, passa a ser extenuado. Veiculado o conteúdo, que é fundamentado no saber partilhado entre os atores da enunciação (narrador e narratário), "a operação cognitiva anula seu objeto no instante em que o apreende!", tal qual afirma Zilberberg (2006, p. 143), ao propor a modalidade do saber como a que provoca a referida extenuação. Com o crer, o objeto - língua, enunciado - mantém-se não apenas preservado, mas fortalecido estesicamente, a ponto de, nessa dimensão, pouco interessarem os fatos. "Lá onde reinam as crenças, os fatos não entram" - eis a alusão feita pelo semioticista (ZILBERBERG, 2006, p. 142). Nas vizinhanças com Landowski, estamos nos regimes de risco: ajustamento e acidente. Para ilustrar o outro lado, aquele do lógos extenuado, favorecedor da programação e da manipulação, lembramos esta afirmaçâo de Zilberberg (2006, p. 143): "Se pensarmos na prática da adivinhação, da charada, do enigma, a operação cognitiva anula seu objeto no instante em que o apreende!". Anulado o objeto, o risco das interações certamente se esvai.

No âmbito das artes, diferentemente, estamos diante da foria de inclinação estetizante, que diz respeito ao modo de perceber o mundo, ao estilo de habitar sensivelmente o mundo. Ela supõe para o corpo um devir orientado em especial ao "ajustamento" que, em se tratando da definição de estilos por meio da contemplação da coerção exercida pela função poética da linguagem (JAKOBSON, 1991), supõe uma relação "amorosa" do falante em relação à língua que ele fala. Landowski (2014) acaba por elucidar essa relação, ao fazer uma carta aberta a Ana Cláudia Oliveira, por ocasião da publicação da obra Semiótica nas práticas sociais - comunicação, artes, educação. Landowski (2014, p.19) alude aí a uma "legítima destituição" de si que pode sofrer a categoria de pessoa, capaz de perder "sua habitual prioridade de princípio" ao ocupar uma posição não mais privilegiada em relação ao objeto, apontando, assim, uma "forma de sensibilidade", uma "consistência estésica" para as coisas. Trazemos para o lógos necessariamente conotado, e conotado semântica e estesicamente, esse princípio de "consistência estésica", a fim de investigar o que as esferas de comunicação oferecem como condições de produção de sentidos, logo, de estilos.

Para a etização, Zilberberg prevê a ativação do sujeito e a não-ativação do objeto - o que entendemos orientar as condições de produção do sentido no interior da esfera midiática da comunicação. Para a estetização, o autor prevê a não-ativação do sujeito e a ativação do objeto, o que certamente é mobilizado no interior da esfera literária da comunicação. Seguindo esses parâmetros sentimo-nos autorizados a pensar na relação de dominância de um regime sobre outro: a etização e a estetização estão em qualquer discurso. É, porém, inevitável pensar que as noções de ativação do objeto (Zilberberg) e de consistência estésica das coisas do mundo (Landowski) reclamam-se mutuamente, logo não se excluem. 


\section{O corpo - imanência e transcendência}

Landowski e Zilberberg contribuem para pensarmos o corpo como imanência e como transcendência. Na imanência está a forma - da expressão e do conteúdo dos textos - fundante da semiose. Mas essa mesma forma é arbitrária, segundo Hjelmslev (1975) e, como arbitrária, ajuda a prever o corpo como uma estrutura aberta. Na abertura está a transcendência, a alteridade, o mundo que está aí, seja axiologizado eticamente, seja percebido sensivelmente. No ato de interpretar o mundo e no modo de percebê-lo, projetam-se estilos. Temos o corpo que, como fundamento da noção discursiva de estilo, faz encarnar-se o ator da enunciação segundo a totalidade discursiva que lhe diz respeito - uma totalidade que pode ser levada em conta como determinada: esfera de comunicação; cena genérica (estilo do gênero); cena enunciativa recorrente e sistematicamente organizada (estilo autoral). É o corpo do ator da enunciação que se funda numa imanência semiótica, definida na correlação com o que transcende a ela.

No perfil semantizado do sujeito, a transcendência diz respeito ao interdiscurso, em que se instalam as formações discursivas, sustento de sistematizações sociais e históricas feitas de aspirações e ideais - estabelecidos conforme temas e figuras. No perfil sensível do sujeito, a transcendência diz respeito ao encontro homem-mundo, na medida em que o sujeito, de agente e performativo no ato de julgar o mundo e de nesse mundo tomar um partido, programando ações, manipulando outros sujeitos, transforma-se: deixa-se ajustar ao que "está aí", entrega-se numa "relação amorosa [...] dirigida rumo às coisas", como diz Landowski na homenagem prestada a Ana Cláudia Oliveira (2014, p. 21). Assim o autor comenta a relação amorosa como "nem exclusiva nem mesmo simplesmente inclusiva" para compará-la com a relação de um jardineiro com o jardim: "Cada um 'serve' o outro. Não especificamente em termos pragmáticos no plano da quotidianidade, mas no sentido mais exigente que cada protagonista deseja incondicionalmente o desabrochar existencial do outro" (LANDOWSKI, 2014, p. 21). Em seguida, o semioticista traz à luz o regime de ajustamento sensível ao descrever aquela relação entre o jardineiro e o jardim, e acrescenta:

Segundo essa perspectiva, o jardineiro da Senhora [...] "ama", quase tanto quanto Vós mesma, as plantas do seu quintal, e inclusive sua fértil terra avermelhada. A paixão dele é vê-las cumprir plenamente seu destino. Por isso, ele cuida de dar-lhes as melhores condições para seu desenvolvimento. E nisso ele mesmo se desabrocha, enquanto jardineiro. De modo tal que, quem sabe, o próprio quintal reciprocamente "ame-o" a seu modo enigmático (LANDOWSKI, 2014, p. 21).

O jardineiro e o jardim: o sujeito discursivo e a expressão linguística que, virtualizada no sistema da língua, realiza-se no exercício de construir estesicamente o mundo - eis a aproximação do conceito de ajustamento, feita em relação com a função poética da linguagem (JAKOBSON, 1991), considerada no grau máximo do exercício de 
suas coerções. Na cotidianidade, ao contrário, a partir de Landowski, entendemos ancorarem-se circunvizinhanças relativas aos regimes de programações e de manipulações, tais quais configurados na esfera midiática da comunicação comparada com a literária.

O ajustamento pode ser examinado no uso linguístico, ao remeter a um corpo contingente como o de um falante nativo que procura escrever e escreve num segundo idioma. Landowski, falante nativo do francês, para dirigir-se a Ana Cláudia, ajusta-se à língua portuguesa, como o demonstram as escapadas para o francês que aparecem iterativamente ao longo do texto no uso: do título, Pour A.; do vocativo da abertura, Chère Ana; na nomeação que faz do ato de alastrar-se (épanouissement, accomplissement) - por contágio, o desabrochamento amoroso - daquele que ama para a coisa ou ente amado e vice-versa:

Passo, portanto, sem mais demorar à definição (metalinguística) de "amar" que eu gostaria de submeter a sua crítica. Seria assim: desejar que o outro, qualquer que seja do ponto de vista actorial (pessoa, animal, planta ou cousa), "se desabroche"... e nada mais. Que o amado / a amada se espalhe do mesmo modo que o botão de rosa, um sorriso ou o ipê roxo que "ontem deu flor" no seu bem cuidado quintal! (LANDOWSKI, 2014, p. 21).

A homenagem feita por Landowski a Ana Cláudia permanece na fímbria entre a semiótica e a literatura. Para tanto aponta para o princípio de ajustamento, enquanto o corpo se firma no regime de união com o mundo discursivizado para que a estesia do lógos (da linguagem) e do éthos (do ator da enunciação) desponte segundo uma tonicidade alta. Salta então o próprio Landowski da programação pressuposta às coerções do gênero "carta aberta" para adentrar a surpresa que, no lugar de garantias, oferece o risco da obscuridade e da ambiguidade do sentido, tal qual sugeridas no poema que, mote dos comentários, abre-se com estes versos: "Senhora, eu vos amo tanto / Que até por vosso marido / Me dá um certo quebranto...".

Mantido o epíteto "Senhora" e mantido o tratamento cerimonioso de segunda pessoa do plural, "Vós", Landowski desenvolve outro ajustamento - desta vez com o próprio poema, que é de Mário Quintana. Mediante os movimentos de construção da homenagem - que, à moda de carta aberta desenvolve um ensaio teórico sobre as interações de risco - compõese a experiência do ajustamento. O semioticista permite-se deslocar-se para o lugar de amante e ajusta-se a ele. Envolve então a terra avermelhada do quintal da Senhora, o jardim, o jardineiro da Senhora e a própria Senhora (cuja voz se faz ouvir no partilhamento sensível levado a efeito). Desloca-se Landowski, o enunciador no papel temático do epistológrafo, para o lugar do poeta Mário Quintana. Cria para si, o semioticista, um não-lugar ou um lugar de limiar, propício ao ajustamento sensível com o outro e com a consistência estésica das coisas do mundo. Em outro quadro do pensamento semiótico, Zilberberg aponta para o fato da estetização dos corpos, que supõe a não-ativação do sujeito e a ativação do objeto. 
Emparelhado ao viés estésico de observação de mundo está o viés ético ou a "etização" segundo Zilberberg. No viés ético, encontramos pontos que confinam com o que Landowski entende por programação e, em especial, por manipulação, tais quais identificáveis na esfera midiática da comunicação. Dessa esfera, o editorial certamente se firma como de etização dominante (Zilberberg) e, no quadro do pensamento landowskiano, como de manipulação prevalecente.

\section{DEPOIS DAQUELE BEIJO}

Ao exibir no capítulo final da novela "Amor à vida" um beijo amoroso entre dois personagens masculinos, a TV Globo atendeu a uma demanda que se intensificava nos últimos anos (...) Em que pese a presença regular da temática gay na teledramaturgia nacional, levantava-se a reivindicação de um ato que selasse de maneira convencional o amor entre pessoas do mesmo sexo (...) Este ato, segundo as convenções do gênero, é o beijo. Nada mais clássico, com efeito, do que as cenas finais em que galãs e heroínas longamente tocam seus lábios em sinal de união afetiva (Folha de S. Paulo, 05/02/2014, Primeiro Caderno, p. A2).

O narrador, actante definido tematicamente como o editorialista, esboça vetores do estilo do gênero no texto que temos à mão. O preenchimento semântico do actante, sujeito enunciador desdobrado na voz do narrador, é levado a efeito por meio dos papéis temáticos desempenhados por esse sujeito discursivo. Esses papéis remetem ao arranjo implicativo ( $x$, logo y) desenvolvido na argumentação pelo "sujeito da narração" para subsidiar figuras e temas no enunciado. Enquanto se destaca a lógica de causa e efeito orientada para persuadir, são retomados noticiário e telenovela, aos quais se imprime um tratamento ético.

Greimas (2014, p. 73), ao discorrer sobre os níveis narrativo e discursivo na geração do sentido, realça-os como seguidos de perto pelo "sujeito da narração". Lembra que o nível discursivo diz respeito "a um dicionário discursivo, um inventário feito de configurações constituídas a partir de universos coletivos e/ou individuais fechados" (GREIMAS, 2014, p. 73, grifo do autor). A regularidade do modo de dizer prevista por essa espécie de inventário acoplada ao gênero certamente se aproxima do que Landowski entende como regime de junção. Também aí se instala o "estoque de temas e motivos" sugerido como "constituído para e pelo uso dos que participam de um universo semântico" (GREIMAS, 2014, p. 74).

O editorial está cravado no inventário temático e figurativo das relações homossexuais tratadas pela mídia, o que leva a um corpo aspectualizado como perfectivo - opiniões acabadas - para o ator da enunciação. É diferente o que ocorre com o tema e a figurativização do tema das relações homossexuais discursivizadas segundo uma estetização dominante ou, par a par com ela, conforme o regime da união, em especial no que diz respeito ao ajustamento. É um ajustamento do sujeito discursivo com a língua textualizada, o que implica a união do enunciador com o enunciado, permeada 
pelo olhar do narrador sobre os atores desse enunciado - grosso modo personagens. Diferentemente do gênero midiático, os corpos se aspectualizam como imperfectivos, como o era Landowski (epistológrafo/ semioticista/ amante) na vivência própria do ajustamento em Pour A...

\section{Entre o vivido e o concebido}

A literatura e a esfera midiática têm cada qual sua identidade preservada a partir das distintas condições de emergência do corpo actorial. Na literatura, o lógos embebido por uma conotação de densidade própria, enquanto instaura a estesia sob os parâmetros da estética, faz emergir, em comparação com o jornal, um corpo de limites borrados o suficiente para fazer evoluir o critério veridictório, em que se apoia a prática midiática, numa verossimilhança. Assim se processa o acolhimento de uma crença primordial em relação ao mundo, vinculada à estetização do lógos e do éthos. Na literatura, um núcleo temático desenvolvido em torno das vicissitudes das relações amorosas homossexuais encontra condições para apresentar-se peculiarmente na intersecção entre o vivenciado e o concebido, se lembrarmos, para esses termos, a homologação entre eles que, feita por Zilberberg (2011, p. 260), emparelha, à intensidade, o vivenciado e, à extensidade, o concebido: "a intensidade é bem mais vivenciada do que conhecida". No interior da comparação feita com a mídia, a literatura firma-se tão mais acolhedora da intensidade dos afetos quanto mais se afasta dos gêneros da imprensa que grassam na extensidade das coisas do mundo inteligivelmente recortadas.

A obra Grande Sertão: Veredas, de Guimarães Rosa (1994), apresenta esses movimentos da significação ao criar os atores Riobaldo e Diadorim, os dois sempre juntos: "Diadorim e eu, nós dois. A gente dava passeios. Com assim, a gente se diferenciava dos outros - porque jagunço não é muito de conversa continuada nem de amizades estreitas: a bem eles se misturam e desmisturam, de acaso, mas cada um é feito um por si" (GUIMARÃES ROSA, 1994, p. 32-33).

A estesia recrudesce diante do inusitado uso do léxico e da sintaxe frasal, entre outros recursos, enquanto Riobaldo, chefe de jagunços do sertão mineiro, narra a história de sua vida a um interlocutor presentificado de modo próprio. Para isso, emerge a relação de ternura amorosa entre o narrador e Reinaldo, o Diadorim, outro jagunço. O corpo do ator Riobaldo (o narrador explícito) instala-se junto ao emprego de uma apóstrofe fluida e iterativa. A voz da narração dirige-se a um tu, senhor, que é instituído como o que detém uma escuta afinada:

Explico ao senhor: o diabo vige dentro do homem, os crespos do homem - ou é homem arruinado, ou o homem dos avessos. Solto, por si, cidadão, é que não tem diabo nenhum. Nenhum! - é o que digo. O senhor aprova? Me declare 
tudo, franco - é alta mercê que me faz: e pedir posso, encarecido. Este caso por estúrdio que me vejam - é de minha certa importância. Tomara não fosse... Mas, não diga que o senhor, assisado e instruído, que acredita na pessoa dele?! Não? Lhe agradeço! Sua alta opinião compõe minha valia. Já sabia, esperava por ela já o campo. Ah, a gente, na velhice, carece de ter algum descanso. Lhe agradeço. Tem diabo nenhum (GUIMARÃES ROSA, 1994, p. 7).

Na assimetria das duas vozes ajustadas (Riobaldo e o senhor convocado), mantém-se proeminente o papel do narrador como aquele que narra os fatos "no átimo" das surpresas. Ajustam-se as vozes, pois firma-se como da ordem da não-previsibilidade a interação entre Riobaldo e seu ouvinte. Um parceiro e outro parecem influenciar-se mutuamente pelo contato e pelo contágio das presenças, como prevê Landowski. A não-previsibilidade da interação está no lugar ocupado pelo destinatário da comunicação: é o lugar de presença e de ausência, de singularidade e de pluralidade concomitantes, o que esboça uma apóstrofe que desempenha função própria.

Se, no último segmento destacado prioriza-se o uso de um presente durativo para os verbos - a fim de afirmar verdades de todos os tempos (como em "a gente, na velhice, carece de ter algum descanso" - ao longo do romance prolifera o uso do sistema verbal pretérito: "E estávamos conversando, perto do rego - bicame de velha fazenda, onde o agrião dá flor. Desse lusfús, ia escurecendo. Diadorim acendeu um foguinho, eu fui buscar sabugos" (GUIMARÃES ROSA, 1994, p.33). Entre o tempo de então (pretérito) e a concomitância ao agora do ato de enunciar (presente), o ator corre riscos próprios ao ajustamento sensível também em relação à própria temporalidade. Enquanto isso, o fato rememorado se fortalece no elã estésico de um "acontecimento extraordinário" que sobrevém ao sujeito (ZILBERBERG, 2011). A memória-acontecimento, mais do que a memória do acontecido (BARROS, 2011) se exacerba e toma posse do sujeito para que ele se apresente num espaço propício às experiências sensíveis. Surge um corpo orientado à temporalidade da percepção, que ilumina a simultaneidade do passado e do futuro interseccionados na duração do presente. O passado é vivido como entrega ao Outro (Riobaldo/Diadorim). O futuro aparece como a dúvida em relação ao destino do homem, sujeito posto na fronteira entre a existência e a inexistência do diabo. O corpo do ator, nesse lugar de limiar, confirma-se como imperfectivo.

Na literatura, a partir da comparação estabelecida com o gênero midiático editorial (o que se viabilizou em torno do tema das vicissitudes das relações amorosas homossexuais), depreende-se a valência plena da conotação sensível do lógos e do éthos. A verossimilhança confirma-se ainda como lugar de ancoragem de um "pensamento paralelo" (GREIMAS, 2014, p. 142) àquilo que é narrado. Ela se afina com um contrato de confiança adensado na crença e por isso transformado em confidência, conforme prevê o mesmo estudo de Greimas (2014). Ao passar da confiança para a confidência, o sujeito 
se afina com as "interações de risco", enquanto se permite experimentar o elã sensivel do que sobrevém a ele como coisa de grande impacto - a linguagem literária.

\section{Tempo e duração: entre paradas e continuações}

Pensando com Zilberberg (2006, p. 133) a relação de contradição entre uma parada (um fazer remissivo) e uma parada da parada (um fazer emissivo), este que "também poderia ser denominado continuativo"; pensando (com o mesmo semioticista) que há um "ajustamento" entre aquilo que é remissivo e aquilo que é emissivo, na medida em que esses dois gestos constituem distintas dimensões do sensível, "misturadas umas com as outras" (ZILBERBERG, 2006, p. 134), logo dimensões somente pensadas como dominância de uma sobre a outra, chegamos ao tempo e à dissensão dele, às "desavenças" do tempo, que, como duração da percepção, funda o corpo estésico.

Diz Zilberberg (2006, p. 136): “Quando o tempo emissivo está em operação, ou seja, é dominante, segue seu curso, o retorno do remissivo é vivido como surpresa, desordem e, evidentemente, interrupção". Despontam outras afinidades entre os pensamentos de Landowski e Zilberberg no valor imprimido ao descontínuo como surpresa - o que, para nós, alinha-se à surpresa própria ao lógos estético, cotejado com o lógos utilitário.

Somos autorizados a avançar na observação do campo de presença como um campo de percepção. Para isso, Zilberberg (2011) coteja o tempo-espaço da percepção, ao discorrer sobre a "interrupção do tempo emissivo" segundo o elemento da surpresa que, na citação feita de Valéry, "me faz sentir diretamente a oscilação entre presente e passado" (VALÉRY apud ZILBERBERG, 2011, p. 136). Nesse ponto, com "um tempo emissivo [que] é regido, ou melhor, dirigido pelo tempo remissivo" (da surpresa), temos o corpo estésico que, ao oscilar entre o passado, o presente e o futuro, "cria o tempo" como duração do sensível.

Na carta aberta a Ana Cláudia, ao definir-se segundo a apreensão imediata do sentido entre sujeitos postos em interação, a qual não excluiu os objetos, Landowski (2014) colocou-se à prova por meio de uma relação arriscada com o Outro. Sob o simulacro de um sujeito que não queria nem deveria calcular resultados de antemão, fez valer o regime do ajustamento, criando o efeito de descoberta mútua entre um e outro actantes, postos em regime de união e realizados na mutualidade dos vividos sensivelmente. Em outro funcionamento da tonicidade de estesia, é equivalente o que se passou naquilo que é narrado por Riobaldo, sujeito que, não inclinado a tornar o outro submisso, ajusta-se a ele (LANDOWSKI, 2005a). Paralelamente, em Grande Sertão, firma-se um enunciador ajustado a tal ponto às virtualidades estésicas da língua, por meio da qual emerge o discurso, que lógos e éthos instalam-se no ambiente narrado segundo o grau máximo da surpresa estésica. Respeitadas as especificidades de cada pensamento que interroga o sensível, o de Zilberberg, relativo aos desdobramentos tensivos, e o de Landowski, 
relativo às interações de risco, fica confirmado que o cotejo entre essas frentes ajuda a investigar o corpo como presença.

\author{
Norma Discini de Campos é professora associada do \\ Departamento de Linguística (FFLCH-USP), instituição \\ à qual se vincula como professora permanente do \\ Programa de Pós-Graduação em Linguística e Semiótica. \\ Como bolsista FAPESP, fez pós-doutorado na Université \\ Paris 8, Vincennes Saint-Denis; orienta mestrado, \\ doutorado, supervisiona pós-doutorado no âmbito da \\ Semiótica e na lateralidade com a Análise do Discurso, \\ ambas de linha francesa, contemplando também as \\ circunvizinhanças da semiótica com a fenomenologia \\ e com o quadro teórico de M. Bakhtin e seu Círculo. \\ normade@uol.com.br
}

\title{
Referências
}

ARISTÓTELES. Arte retórica e arte poética. Rio de Janeiro: Editora Ediouro - Tecnoprint, 1979.

BARROS, M. L. P. O discurso da memória: entre o sensível e o inteligível. Tese de Doutorado Faculdade de Filosofia, Letras e Ciências Humanas, Universidade de São Paulo. São Paulo, 2011.

BARTHES, R. A retórica antiga. In: COHEN, J.et al. Pesquisas de Retórica. Petrópolis: Vozes, 1975, p. $147-221$.

FABBRI, P. Introdução. In: Algiras Julien Greimas. Da Imperfeição. São Paulo: Hacker Editores, 2002.

FECHINE, Y. et al. (orgs.) Semiótica nas práticas sociais - comunicação, artes, educação, São Paulo: Estação das Letras e Cores, 2014.

FIORIN, J. L. As astúcias da enunciação: as categorias de pessoa, espaço e tempo. São Paulo: Editora Ática, 1996.

GREIMAS, A. J.; COURTÉS, J. Dicionário de Semiótica. T São Paulo: Contexto, 2008.

GREIMAS, A. J. Da Imperfeição. São Paulo: Hacker Editores, 2002.

Sobre o sentido II: ensaios semióticos. São Paulo: Nankin: Edusp, 2014.

GUIMARÃES ROSA, J. Grande sertão: Veredas. Ficção Completa. São Paulo: Nova Aguilar, 1994. v. 2. Disponível em: http://stoa.usp.br/carloshgn/files/-1/20292/Grande-SertoVeredasGuimaraesRosa. pdf. Acesso em: 15 de abril de 2017.

HJEMSLEV, L. Prolegômenos a uma teoria da linguagem. São Paulo: Perspectiva, 1975.

JAKOBSON, R. Linguística e comunicação. São Paulo: Editora Cultrix, 1991.

LANDOWSKI, E. Les interactions risquées. In: Nouveaux Actes Sémiotiques. Pulim: Université de Limoges, 101, 102, 103, 2005a. 
Aquém ou além das estratégias, a presença contagiosa. Documentos de Estudo do Centro de Pesquisas Sociossemióticas. Centro Interinstitucional: PUC-SP - USP - CNRS, 2005b.

Pour A. In: FECHINE, Y. et al. (orgs.) Semiótica nas práticas sociais - comunicação, artes, educação, São Paulo: Estação das Letras e Cores, 2014.

TATIT, L. A abordagem do texto. In: FIORIN, J. L. (org.) Introdução à linguística I: objetos teóricos. São Paulo: Contexto, 2002, p. 187-209.

ZILBERBERG, C. Razão e poética do sentido. São Paulo: Edusp, 2006.

Elementos de semiótica tensiva. São Paulo: Ateliê Editorial, 2011.

Artigo recebido em abril

e aprovado em maio de 2017. 